\title{
PERA and GERAM--enterprise reference architectures in enterprise integration
}

\author{
Theodore J. Williams
}

Institute for Interdisciplinary Engineering Studies

Purdue University

1293 Potter Center, West Lafayette, IN 47907-1293 USA,

Phone: (765) 494-7434, Fax: (765) 494-2351,

e-mail:tjwil@ecn.purdue.edu

and

Hong $\mathrm{Li}$

Senior Consultant, Claremont Technology Group, Inc.

111 West Liberty St., Columbus, OH 43215 USA

Phone: (614) 628-4800, Fax: (503) 628-4801,

e-mail: Hong_Li@clmt.com

\begin{abstract}
This paper describes PERA (the Purdue Enterprise Reference $\underline{\text { Architecture) and }}$ shows its relationships to GERAM (the Generalized Enterprise Reference Architecture and Methodology). PERA was developed at Purdue University during the period 1989-94. GERAM was developed by the IFAC/IFIP Task Force to illustrate that all "complete" enterprise reference architectures should map together and have comparable characteristics and capabilities.
\end{abstract}

\section{Keywords}

Enterprise integration, reference architecture, computer integrated manufacturing, program or project architectures, physical system architectures, PERA (Purdue Enterprise Reference Architecture), GERAM (Generalized Enterprise Reference

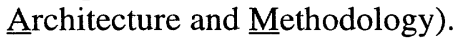


This paper will initially describe some of the systems engineering aspects of enterprise integration and use them to show the development and use of PERA (Purdue Enterprise Reference Architecture). We will then show how PERA combines with other available enterprise reference architectures (CIMOSA and GRAI-GIM) to give GERAM (the Generalized Enterprise Reference $\underline{\text { Architecture }}$ and Methodology). It will be seen that PERA contains all of the capabilities of GERAM but the latter's presentation is influenced by the individual characteristics of the three architectures mapped within it.

Enterprise integration can be defined as: --the coordination of the operation of all elements of the enterprise working together in order to achieve the optimal fulfillment of the mission of that enterprise as defined by enterprise management. Note the emphasis on all and on optimal. All elements means:

1. All direct mission enabling elements of the enterprise (that is, all of the equipment providing the product and/or service functions which comprise the mission to the customers of the enterprise),

2. All control and information function enabling elements (equipment again), and

3. All humans involved in the enterprise (humans may serve along with the equipment in either the direct mission enabling functions and/or the control and information functions which monitor and control the mission elements).

Please note that in this context, the word enterprise comprises the whole of how a business operates as just described here and not just the business process (or management type) functions as indicated by the title -- Enterprise/Control Integration. Unfortunately, enterprise integration, as used in many of the applications being carried out today, discusses only the information and control aspects of the overall enterprise which will be described in this paper.

We should note also here that enterprise integration subsumes unto itself all of the "buzz word" techniques being paraded by consulting groups today. Terms such as: agile manufacturing, business process reengineering, CIM [computer integrated manufacturing], etc., are used. All of these attempt to skim the cream from the milk of overall enterprise integration, but all are doomed to failure because they are short-cut, incomplete, partial solutions to a much larger problem.

All of the benefits claimed for those short-cut solutions obviously apply to overall enterprise integration itself. It would be repetitious to list them again here since they have been broadcast so widely and so often by the practitioners of the other proposed solutions. Nevertheless, they must all be considered to apply.

Let us now discuss some systems engineering concepts which will explain what we have just said above and lay out the path to enterprise integration fulfillment. 


\section{THE SIMPLIFYING CONCEPTS OF SYSTEMS ENGINEERING IN ENTERPRISE INTEGRATION}

What we will present here are a set of axioms of systems engineering [Williams (1961), Checkland (1985), Sage (1992), and Thome (1993)]. Axioms are elements of intuitive or logical knowledge which cannot be proven. They can only be disproved by a counter-example. The concepts presented here are generic, that is, they apply to any and every enterprise, everywhere. It is this genericity which makes the practice of enterprise integration engineering possible at all, even with computer help.

\subsection{Concept I -- The Universality of these Concepts}

While the early work in CIM, and of enterprise integration as well, was largely confined to the field of discrete manufacturing, it can readily be shown that the basic principles involved apply to any enterprise, regardless of its size and mission or any of the other such attributes involved. These are generally principles which apply to all aspects of the field of systems engineering. In addition, it is a mistake to confine the integration discussions to information and control systems alone. Often there are problems within the mission system (manufacturing or other customer product and service operations) whose solution would greatly ease the overall plant system problem (i.e., it must involve both information and mission).

\subsection{Concept II -- The Mission}

Every enterprise must have a business or mission (the production and distribution of a product(s) or service(s)) which satisfies the needs or desires of one or more customers, otherwise it must eventually fail. This mission must be established and administered by a central authority of the enterprise.

This is almost self-evident. However, it is very important that the central authority (management?) articulate this mission in a succinct, well-understood and motivating manner. This statement is commonly called the Mission, Vision, and Values of the enterprise.

Note also that this mission must usually be accomplished in competition with other enterprises vying for the same customer markets. Hence the need for the optimality in our definition of enterprise integration.

\subsection{Concept III -- Separation of Functions}

In terms of their functional analysis there are two and only two basic classes of functions in the operation of any enterprise. These are:

1. Those involved in operating the "processes" which result in producing the "product" which fulfills the enterprise's mission, i.e., the customer product or service business in which the enterprise is engaged. In the manufacturing plant these would include all material and energy transformation type tasks and the movement and storage of the same materials, energy, goods in process, and products.

2. Those involved in the "control" of the mission in an "optimal" manner to achieve the necessary economic or other gains which assure the viability or 
continued successful existence of the enterprise. These comprise the collection, storage and use (i.e., transformations) of information concerning the business processes in order to control them, i.e., to develop and apply necessary changes to the business processes to achieve and maintain their required "optimal" operation. Thus it includes all planning, scheduling, control, data management, etc., functions. Likewise, these tasks also include all those functions normally attributed to management and related operations.

These two classes of functions interconnect only in (a) operational data collected by sensors which obtain signals which are representations of the status of the operating variables of the mission enabling equipment and its "products" being produced. This data is then transmitted to the information and control tasks; and (b) the operational commands transmitted from the information and control system to the mission enabling equipment to change its operation toward "optimality" as it exists at that moment.

Figure 1 diagrams the definitions above. Note that the use of italics on several of the terms used here indicates that they are defined in the most general manner possible in order to cover the extremely wide range of aims, methods and conditions covered.

These concepts form the basis for our further discussion of enterprise integration.

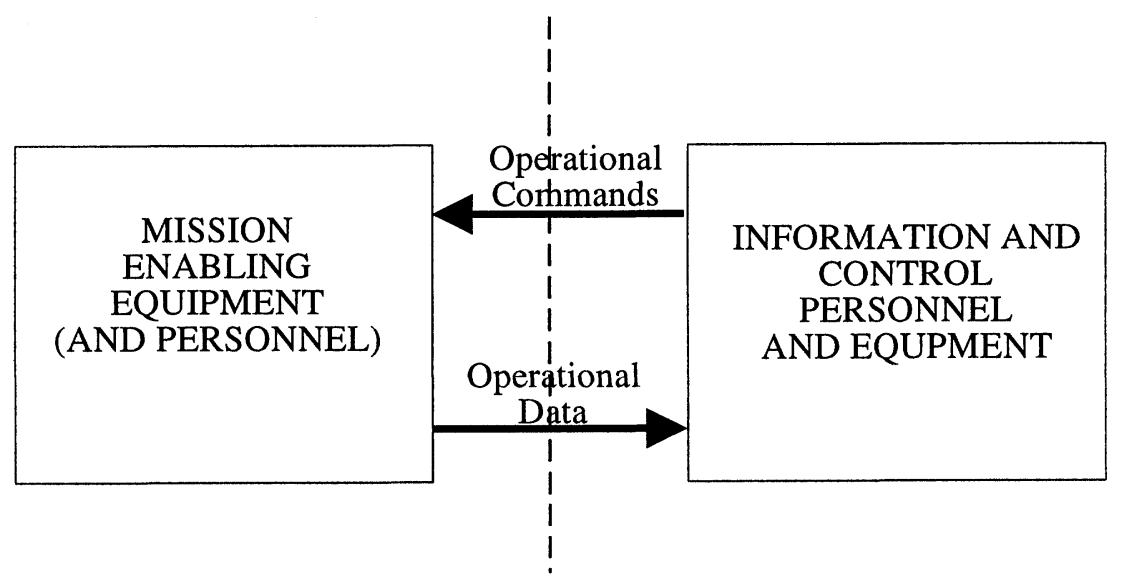

MISSION-INFORMATION AND CONTROL INTERFACE

Figure 1 The two classes of enterprise functions and their interconnection

\subsection{Concept IV -- Networks of Tasks}

1. Normally, information or data will undergo multiple transformations, i.e., many separate tasks (where a task defines each transformation) in fulfilling the information-handling requirements for an enterprise or CIM system. These transformations or tasks are usually successive operations forming sets of sequential and parallel networks. 
2. The same is true of the material and energy transformation tasks for fulfilling the physical production or plant operations requirements for the enterprise.

3. In each case the networks involved can be combined, if desired, to achieve one major network of each type (Informational Transformations or Material and Energy Transformations, respectively), the totality of which defines the functionality of the enterprise or other business entity being considered (i.e., the totality of the information network, plus the manufacturing networks, both of which can be developed separately but used conjointly).

4. The two networks interface in those tasks that develop operating variable states or status from the manufacturing processes (sensors) and those that deliver operational commands to the operational units (actuators and related devices). Except for these tasks and their related requirements, which do affect the other networks, each network can be developed independently of the other. Figure 1 illustrates this concept.

5. Initial functional analysis or general study of either or both classes of functions above can be carried out without knowledge or concern of how they will ultimately be implemented in the operating enterprise.

The last item is vital to the necessary simplification of the overall work involved in enterprise integration planning, design and implementation.

\subsection{Concept V -- The Place of the Human}

For many technological, economic, and social reasons, humans are involved in the implementation and execution of many business processes of all types in both classes above. Others, of course, may possibly be automated or mechanized. Thus there must be three classes of implemented tasks or business processes:

1. Those of the information and control type which can be "automated" by computers or other "control" devices.

2. Those of the mission tasks or business processes which can be automated or rather mechanized by the "mission fulfillment" equipment.

3. Those functions carried out by humans, whether of the control or mission fulfillment class.

There must be a simple way of showing where and how the human fits in the enterprise and how the distribution of functions between humans and machines is accomplished.

To reiterate for clarity, there are only two classes of tasks when they are considered functionally, but there are three classes of implementations because humans may be asked to implement any of the tasks from either functional class.

Figure 2 explains the definitions involved in Concept III and opens the way for our discussion below of how to determine the place of the human in the integrated enterprise, indeed of any enterprise anywhere. We start by remembering that in ages past all of the tasks of operating an enterprise were carried out by humans. Eventually, some of the mission enabling tasks were carried out by mechanization employing animal power. Still later, close to the present time, these mechanizations were, to a large extent, enabled by mechanical power. It is only in very recent times, in historical terms, that, first, mechanical, then, electrical, and 
finally computer-based devices have been introduced into the fulfillment of the information and control tasks of the right-hand side of Figure 2.

Figure 2 represents only those functions which were mechanized or automated. As noted above, many of these functions, on both sides of the diagram, are still carried out by humans. Thus Figure 3 expands Figure 2 to show the humanimplemented tasks as encompassing both types.
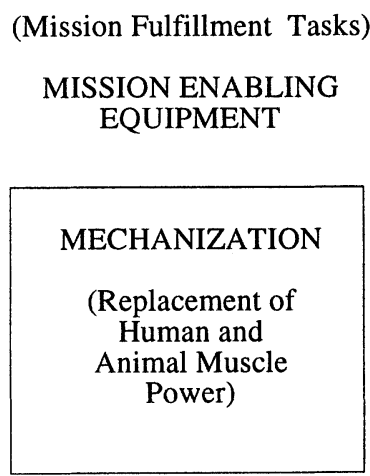

(Information and Control Tasks)

INFORMATION AND CONTROL EQUIPMENT

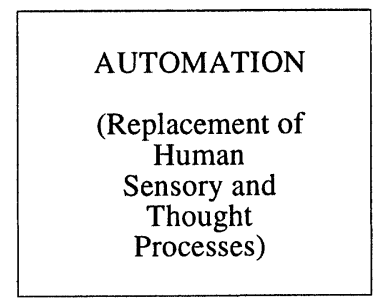

Figure 2 Definition of automation and mechanization in relation to implementation of the tasks of the enterprise

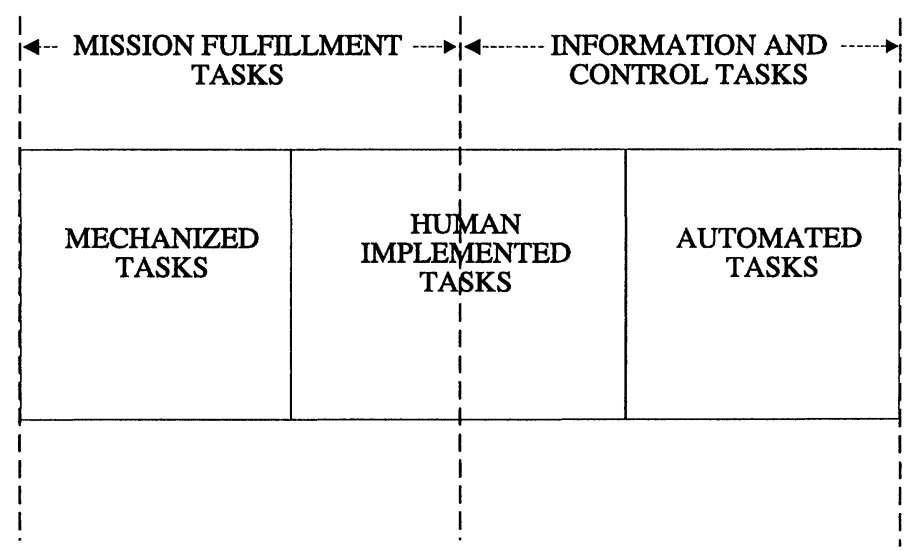

Figure 3 Human implemented tasks may be either of the mission fulfillment or of the information and control type

The reader will immediately respond that many human tasks seem to involve both types for one apparent task. But, please note that all such tasks can be readily broken down into the requisite two. As an example, operating a machine tool 
involves controlling the cutting tool (control) and handling the work pieces (material handling).

Thus there are a large number of tasks on each side of Figure 1. Some, of each class, can or must be done by humans. Figure 4 outlines one method of making the necessary choice between human implementation or automation. (Let us use the word automation in the rest of this paper to indicate both automation and mechanization as used earlier. This will make our further discussion much less awkward.)

The procedure to be used here works as listed in the following discussion. To show the true place of the human in the implementation of the enterprise functions, there is a need to assign the appropriate ones of these tasks and functions developed on both sides of the diagram of Figure 1 to the human element of the system. This can be done by considering the functional tasks as grouped in three boxes as shown in Figures 3 and 4 . These are separated by defining and placing sets of three dashed lines in the graphical architecture representation. This action will separate the two earlier functional analysis streams of Figure 1 into three as shown in Figure 4 and thus assign the tasks or functions involved to the appropriate boxes. The resulting boxes then define the automated information and control tasks which become the Information and Control Systems functions and the automated manufacturing tasks which become the Manufacturing Equipment System or the Customer Product and Service Equipment Systems functions. The remainder (non-automated) become the functions carried out by humans as the Human and Organizational System.

The Automatability Line (see Figure 4) shows the absolute extent of pure technologies in their capability to actually automate the tasks and functions. It is limited by the fact that many tasks and functions require human innovation, and so forth, and cannot be automated with presently available technology.

The Humanizability Line (see Figure 4) shows the maximum extent to which humans can be used to actually implement the tasks and functions. It is limited by human abilities in speed of response, breadth of comprehension, range of vision, physical strength, and so forth.

Still a third line is presented which can be called the Extent of Automation Line (see Figure 4) which shows the actual degree of automation carried out or planned in the subject Enterprise Integration system. Therefore, it is the one which actually defines the boundary between the Human and Organizational System and the Information and Control System on the one hand, and the boundary between the Human and Organization System and the Manufacturing Equipment System or Mission Enabling System on the other side. 


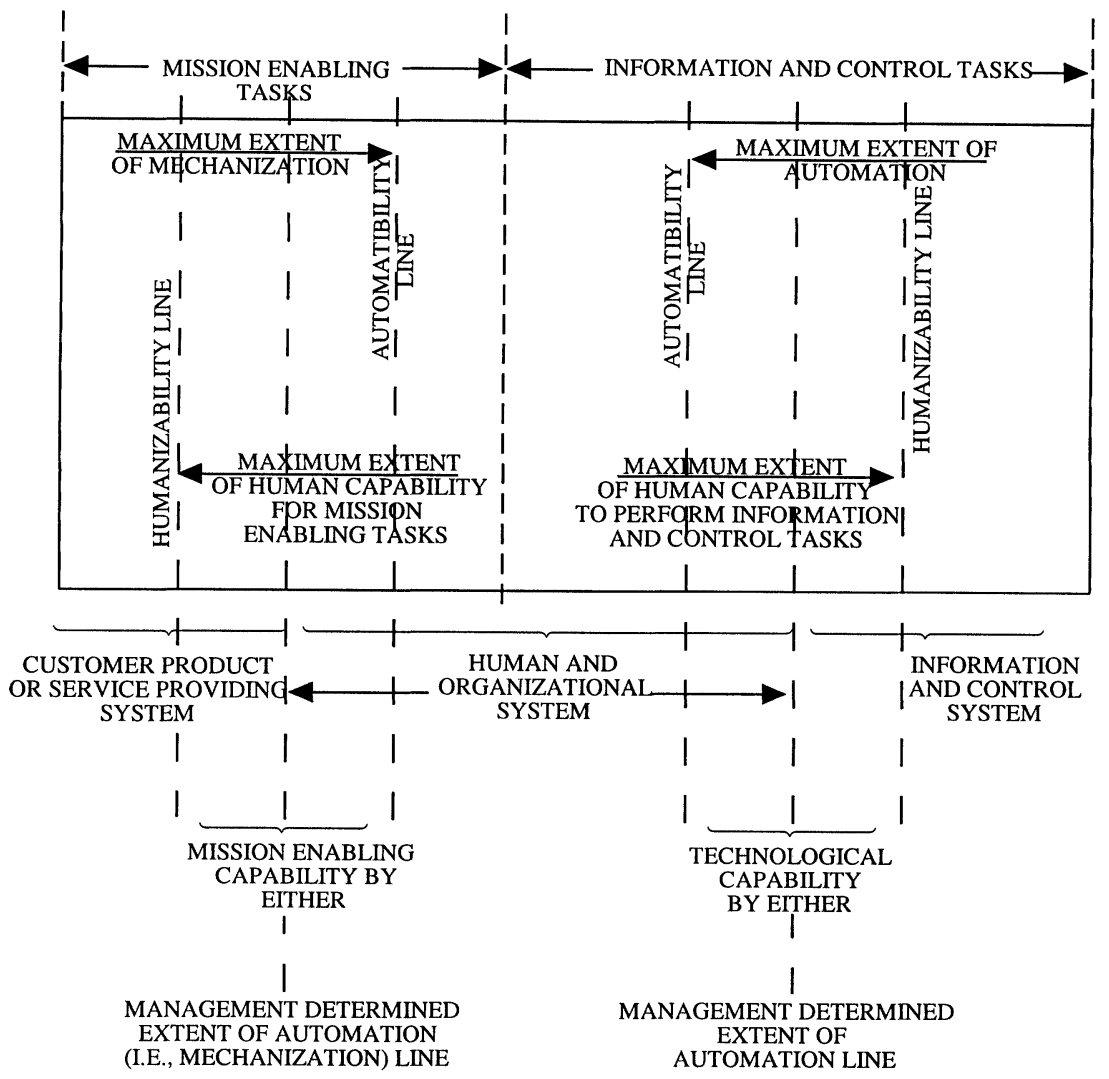

Figure 4 Determining the place of the human in the enterprise

The location of the Extent of Automation Line is influenced by

a) Economic

b) Political

c) Social
-- Customs
-- Laws \& Directives
-- Union Rules

as well as Technological factors. The establishment of the Extent of Automation Line is therefore a management rather than an engineering task.

The Automatability Line showing the limits of technology in achieving automation will always be outside of the Extent of Automation Line with respect to the automation actually installed (see Figure 4). That is, not all of the technological capacity for automation is ever utilized in any installation for various reasons. Thus, the Human and Organizational System is larger (that is, more tasks or functions) and the Information System and Manufacturing Equipment System 
are smaller (less functions) than technological capability alone would allow or require.

\subsection{Concept VI -- The Life Cycle}

1. All enterprises, of whatever type, follow a "life cycle" from their initial concept in the mind of an entrepreneur through a series of stages or phases comprising their development, design, construction, operation and maintenance, refurbishment or obsolescence, and final disposal.

2. Not only does this life cycle apply to the enterprise but also to the enterprises' products as well. Thus, carried further, one enterprise can be the product of another. For example, a construction enterprise could build a manufacturing plant (enterprise) as its product. The manufacturing plant would then manufacture (produce) its own product, such as an automobile. The automobile also has its own life cycle, which goes through similar steps to those discussed here.

The simplest representation of Concept VI-1 is the ladder of phases of Figure 5. The simple list of Concept VI-1 has been expanded somewhat at the top since, as will be seen, we feel these phases must be so expanded because of their role in enterprise engineering planning. It must be immediately stated that no engineering effort is ever only once straight through, recycles always occur -- enterprise engineering in particular is no exception. However, such recycles are left off of this and the succeeding diagrams since we do not know beforehand where they will occur and also in order to avoid cluttering up our diagrams.

\subsection{Concept VII -- Planning and Organization of the Integration Effort}

1. Because of the magnitude and complexity of any enterprise integration project, a major engineering and operations planning effort must be accomplished prior to any actual integration work. This is commonly called a "master plan."

First and foremost, management goals, hopes and dreams for the results of the project and for further enterprise operation must be included in project planning and execution. These are commonly called the Mission, Vision, and Values statement of the enterprise and the project.

All aspects of the enterprise and its operation must be considered in the enterprise integration project analysis.

2. Once the integration of all of the informational and customer product and service functions of an enterprise have been properly planned (the Master Plan), the actual implementation of such an integration may be broken up into a series of coordinated projects, any and all of which are within the financial, physical, and economic capabilities of the enterprise, which can be carried out as these resources allow as long as the requirements of the Master Plan are followed. When these projects are completed, the integration desired will be complete.

3. All tasks should be defined in a modular fashion, along with their required interconnections, so they may later be interchanged with other tasks that carry out similar functions but in a different manner should this be desirable. 
4. Again because of the magnitude and complexity of the overall project and the unfamiliarity of most engineers with such an effort, a detailed generic methodology for such projects is very important.

5. This methodology (as explained below) can be represented or modeled by an enterprise integration reference architecture.

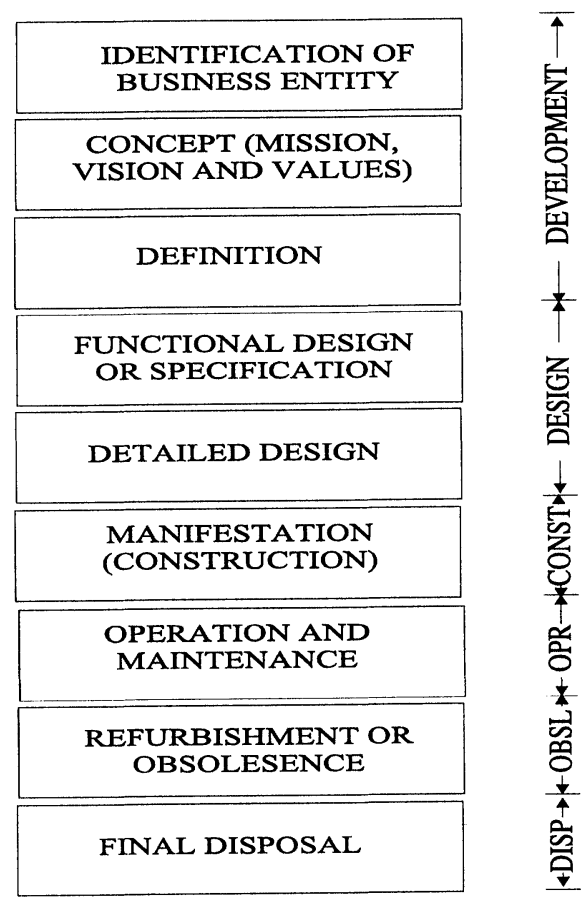

Figure 5 The simplest life cycle

\section{THE METHODOLOGY}

As stated in Concept VII, a vital necessity for successful enterprise engineering is a simply expressed and easily understood methodology. Complexity we cannot diminish. It is present by definition in all massive projects, of which enterprise integration is a prime example. But complexity should be handled by the computer system which is admirably suited for such a task.

The steps or phases of the Purdue Methodology for Enterprise Integration follow the expanded set listed in Figure 5. These combined with the seven concepts listed earlier result in the Methodology which is outlined in Table I and Figures 6 and 7. It will be noted by the reader that the diagram of Figures 6 and 7 is called an Architecture as are some of its subdivisions. As stated above, they are a graphical model of the methodology. However, a better title was desired since there can be a 
multitude of models developed in the many processes involved in the work indicated in this diagram.

Table I Phases of the Enterprise Integration Project and of the Subject Enterprise Entity -- the Enterprise Entity Life Cycle

\begin{tabular}{cll}
\hline Phase & Title & Brief Description \\
\hline 1 & $\begin{array}{l}\text { Identification of the } \\
\text { Enterprise Business Entity }\end{array}$ & $\begin{array}{l}\text { Establishment of Identity and } \\
\text { Boundaries of the Enterprise Entity } \\
\text { Being Considered }\end{array}$ \\
2 & Concept of the Project & $\begin{array}{l}\text { Mission, Vision and Values of the } \\
\text { Enterprise Entity, Operational Policies } \\
\text { to be Followed }\end{array}$ \\
& Definition of the Project & $\begin{array}{l}\text { Identity Requirements, Tasks and } \\
\text { Modules and Develop Flow Diagram } \\
\text { or other Models of the Enterprise } \\
\text { Entity }\end{array}$ \\
& $\begin{array}{l}\text { Specification or Preliminary } \\
\text { Design of the Project }\end{array}$ & $\begin{array}{l}\text { Identify Human Tasks, Initial Choice } \\
\text { and Specification of Human } \\
\text { Organization and of Information and } \\
\text { Control Equipment and Mission } \\
\end{array}$ \\
& Fulfillment Equipment
\end{tabular}

Note (1) The Master Plan Involves All of the Above Information

Detailed Design of Human

and Organizational, Information and Control, and

Customer Product and

Service Components of the

Enterprise
Completion of All Design in Detail Needed for Construction Phase

Note (2) Phases 4 and 5 are Often Combined as One Design Phase. However, the Differences in Effort level and the Need for Master Plan Completion at the End of Phase 4 Indicates Their Desirable Separation Into Two Phases

6 Implementation or Construction, Test and

Commissioning Phase

7 Operations Phase

8 Decommissioning
Conversion of Detailed Design to Actual Plant Elements, Their Testing, Operational Trials and Acceptance or Commissioning

The Period of Time While the Enterprise Entity is Carrying Out Its Mission as Prescribed by Management

The Enterprise Entity Has Come to the End of Its Economic Life, Must be Renovated or Dismantled 


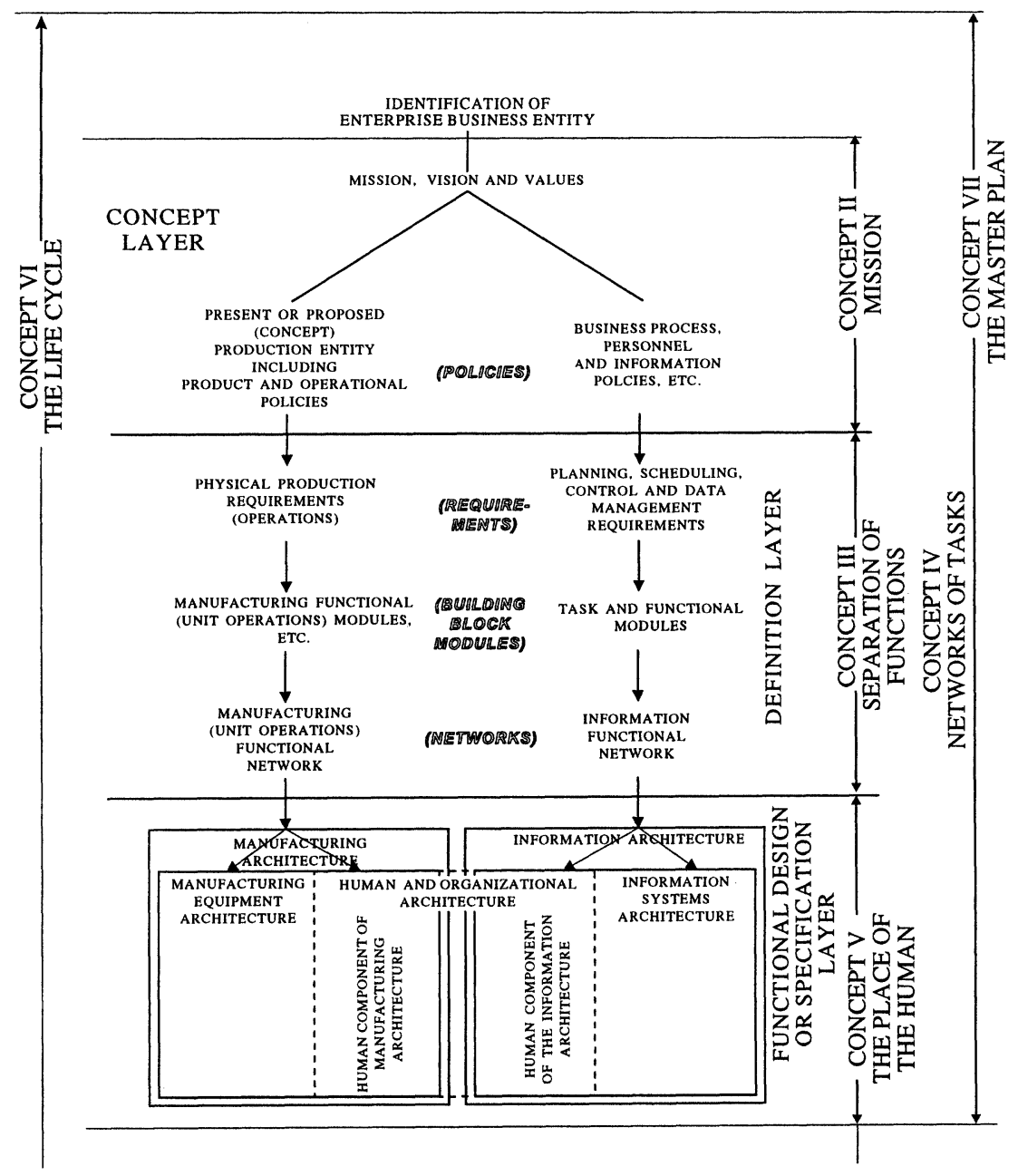

Figure 6 Development of Purdue methodology and the Purdue Enterprise Reference Architecture

Since the diagram represents the structure of the project of planning, designing, implementing and operating an enterprise, it was decided to call it an architecture. An architecture is, of course, a description (often graphical) of the structure of something. Since the later applications are usually of a physical entity rather than 
a project, it was decided to call the project conduct structure a Type II architecture in contrast to the physical example (Type I).

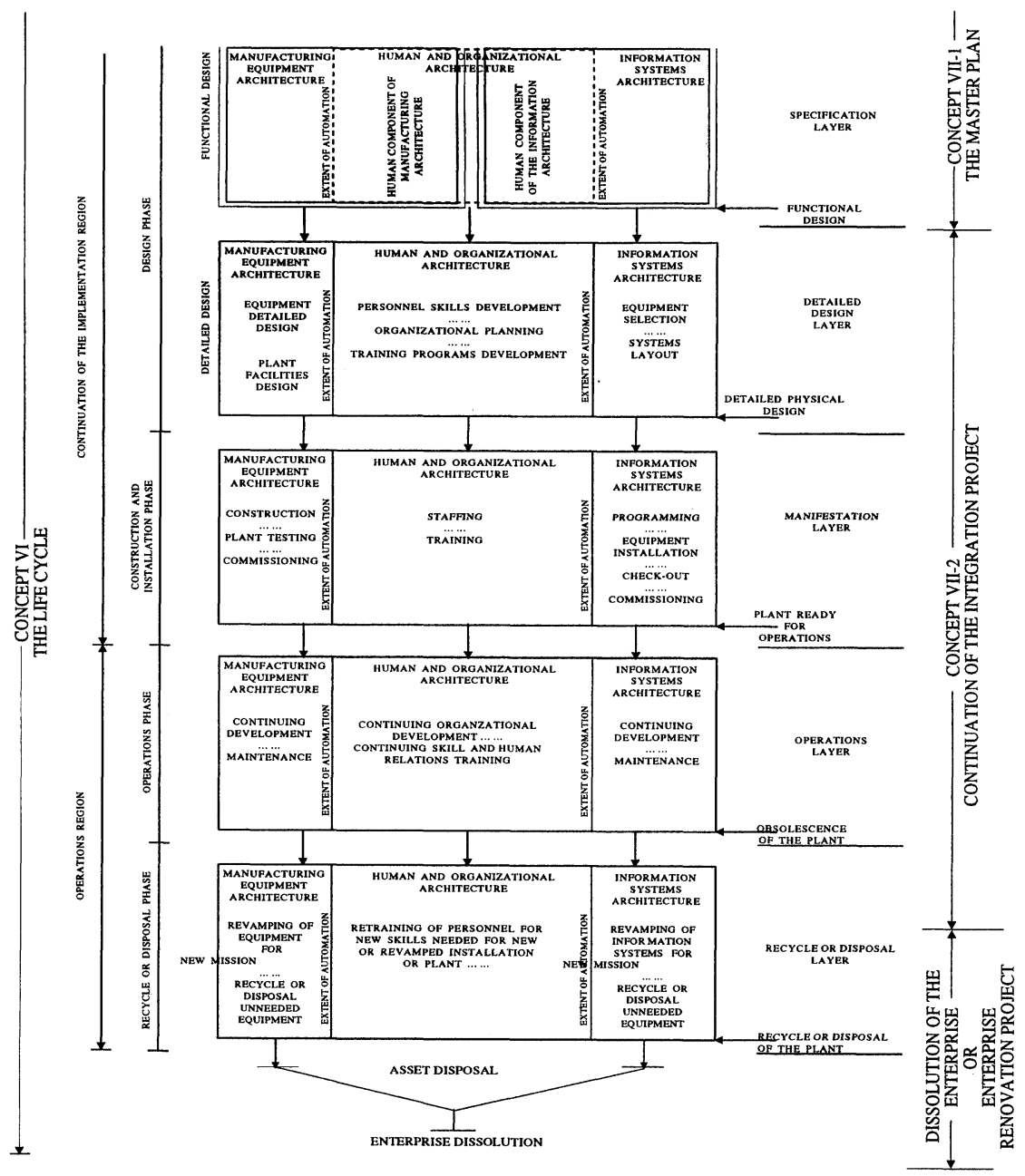

Figure 7 Continued development of the Purdue methodology and the Purdue Enterprise Reference Architecture

Likewise, the parts of the diagram which described the development of the Customer Product and Services System and the Information and Control System became subarchitectures of the overall diagram. The complete architecture, as developed, was labeled the Purdue Enterprise Reference Architecture [Williams (1994)] because of its genericity and overall applicability.

The methodology can be described as follows: 
The Methodology of Enterprise Integration presents a set of instructions (text, computer programs and tools, models, graphical diagrams, etc.) which gives a step-by-step aid to the user in carrying out all needed aspects of the execution of the life cycle phases or steps of the enterprise entity integration project. In this way it describes the processes of enterprise engineering and integration.

As noted earlier, the first task of the methodology is to assure that the Master Plan to be developed by the enterprise integration-planning team is complete, accurate and properly oriented to future business developments. As Table I describes, the Master Plan summarizes all the information developed in the first four phases of the life cycle and presents these for management approval along with the division of the overall projects into a manageable set of smaller, subprojects.

There are two reasons for the selection of this location to define the Master Plan [Williams (1994), Williams, et al. (1996)]. This represents the maximum of information available from the relatively small planning team, thus the most information for the minimum costs. Likewise, the next phase, detailed design, will involve a major increase in manpower and costs for the project. Thus this point becomes the last chance decision point which management has to review the project before major costs are expended.

The methodology must also provide a number of checklists to assure that the Master Plan developed by a company integration-planning team is complete, accurate, properly oriented to future business developments, and carried out with the minimum of resources, personnel and capital. This needed methodology would thus:

1. Describe the tasks to develop the Master Plan including its continual renewal.

2. Define the necessary quantity of information and data.

3. Specify the informational, the human-organizational, and the customer products and services interrelationships in the integration considered.

4. Consider and address management concerns.

5. Present relevant economic, cultural, and technological factors.

6. Detail the extent of computer support required.

7. Detail estimated costs, benefits and timing of the proposed integration project.

Once the Master Plan has been prepared, submitted to management and the continuation of the project approved, the methodology will continue to provide guidance and advice on the conduct of all the succeeding phases. Previous work has shown that the conduct of the enterprise integration project and thus this methodology can be generically prepared to a very high degree [Bernus, et al. (1996)]. Of course, the fine details of any project will vary from each other but, as noted, the overall details are amazingly generic [Rathwell and Williams (1996)].

Figures 6 and 7 provide a diagram which is effectively a model of the methodology described here. The methodology and this diagram are derived from the concepts presented here. Note the following:

1. The Concept Phase (an unfortunate second different use of this word) develops the details of the Enterprise Mission of Concept II. Figure 8 shows 
the place of Upper and Middle Management (Steering Committee) in preparing this part of the Master Plan. This material is presented to the succeeding investigations in the form of the policies needed to carry out the mission of the enterprise.

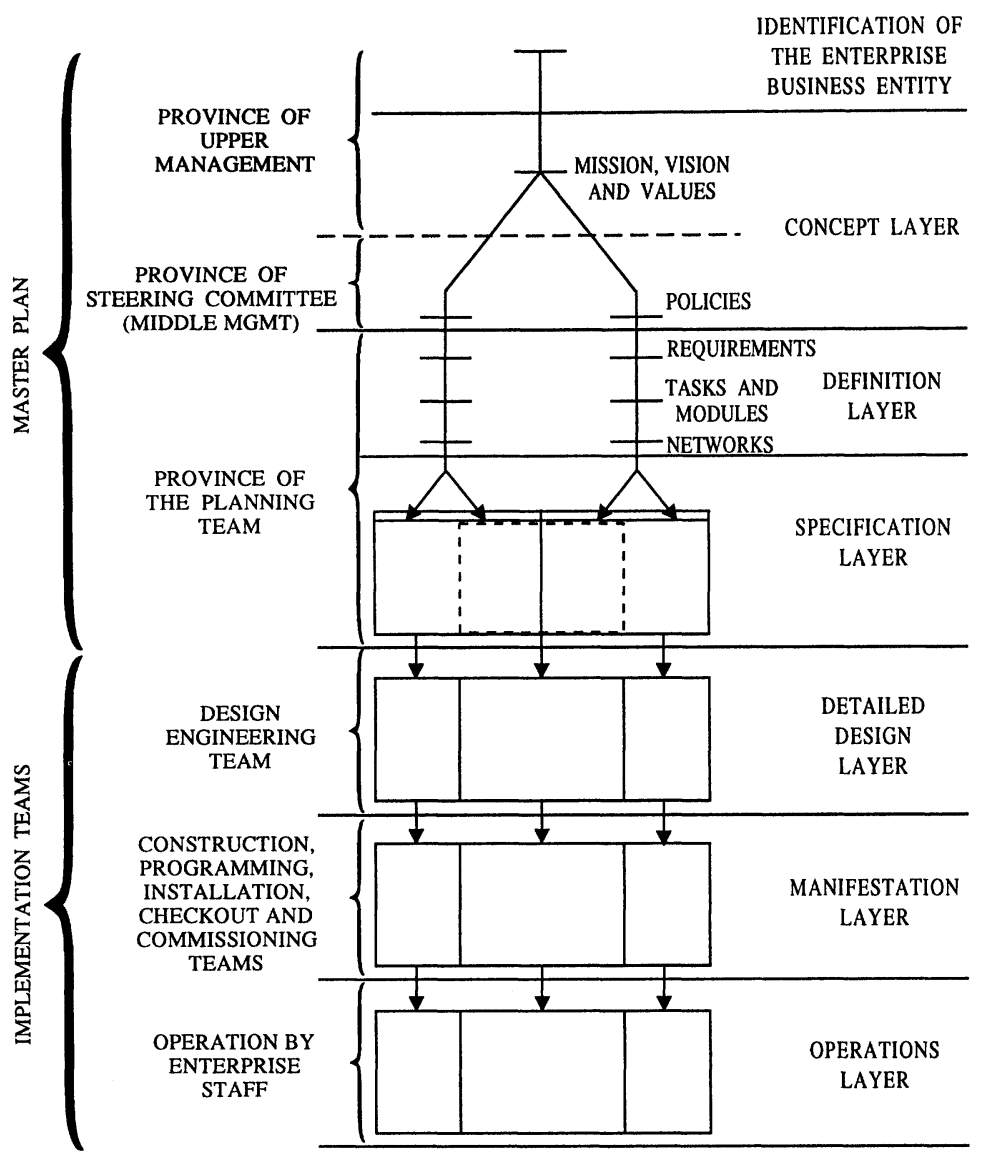

Figure 8 Who carries out the tasks involved

2. The major work of developing the Master Plan is carried out by a Planning Team whose members are expert in the technology involved but also made up of members of the future operation staff of the enterprise to the highest extent possible. From the Policy and Mission Statements they use the lead of Concepts III to VI to evaluate the proposed project and prepare the Master Plan itself. The Definition Layer (Figure 6) shows the steps involved in modeling the networks for both the Information and Control and the Customer Product and Service Systems. The Functional Design or Specification Layer follows the structure of Figure 4 to show how the tasks of the enterprise are 
assigned and the resulting specification prepared. The actual implementation systems designs must be carried far enough forward by the Planning Team to permit a detailed enough cost estimate for a management decision on whether or not to continue with the proposed enterprise integration engineering project.

3. The Master Plan needs to be in two parts: (a) a management version briefly presenting the project's goals, benefits and costs along with the collection of subprojects which can be carried out with the resources of the enterprise at hand as noted in Concept VII-2; and (b) a much more detailed version which presents all the information necessary for the Detailed Design Staff personnel to begin the detailed design work noted in the next phase. This is shown in Figure 9.

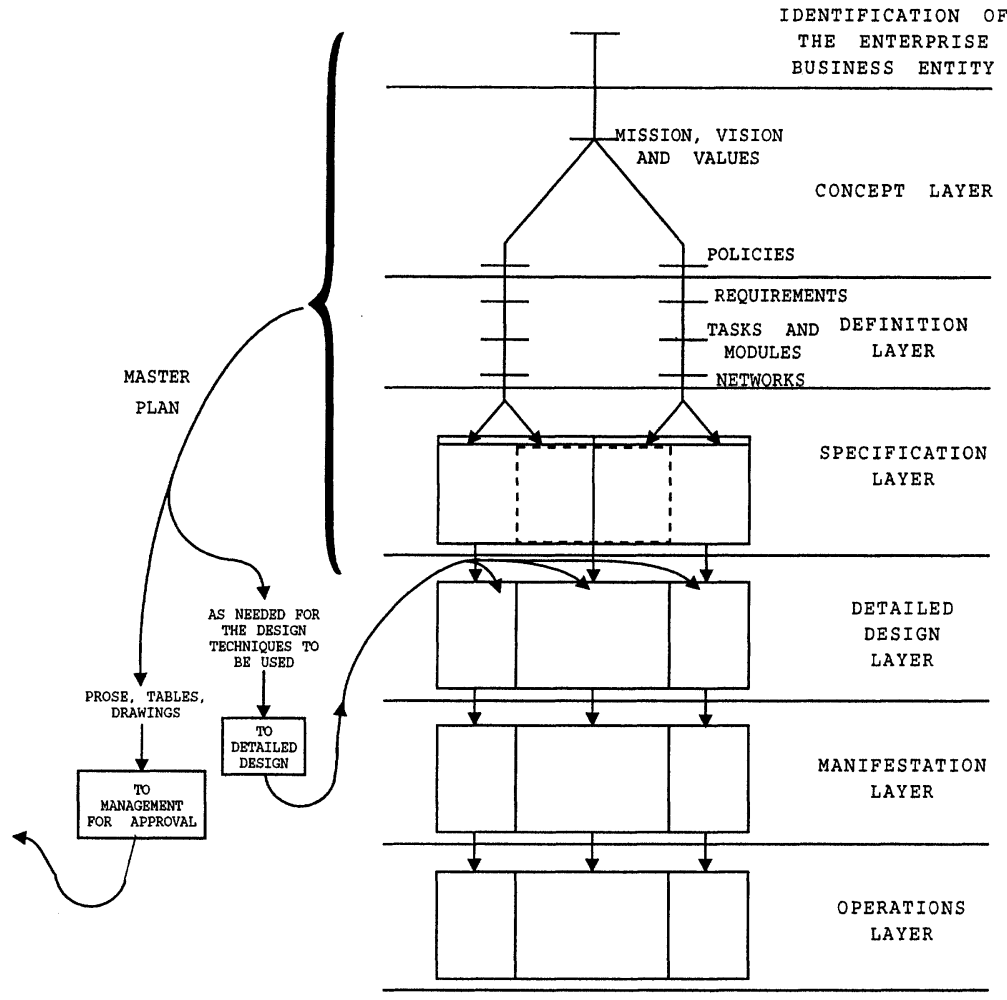

Figure 9 The place of the Master Plan in the PERA structure

4. There are many computer-based design suites, previous successful design examples in computer-readable form, databases of design requirement specifications which conform to local and national laws, etc., which are available for continuation of the project. These are often collected together in the form of Computerized Work Benches for the convenience of design and construction staffs. Some example aids available are indicated in Figure 10 in 
both formal and informal programs and documents. Figure 7 indicates the tasks to be performed in each area of the diagram as the work progresses.

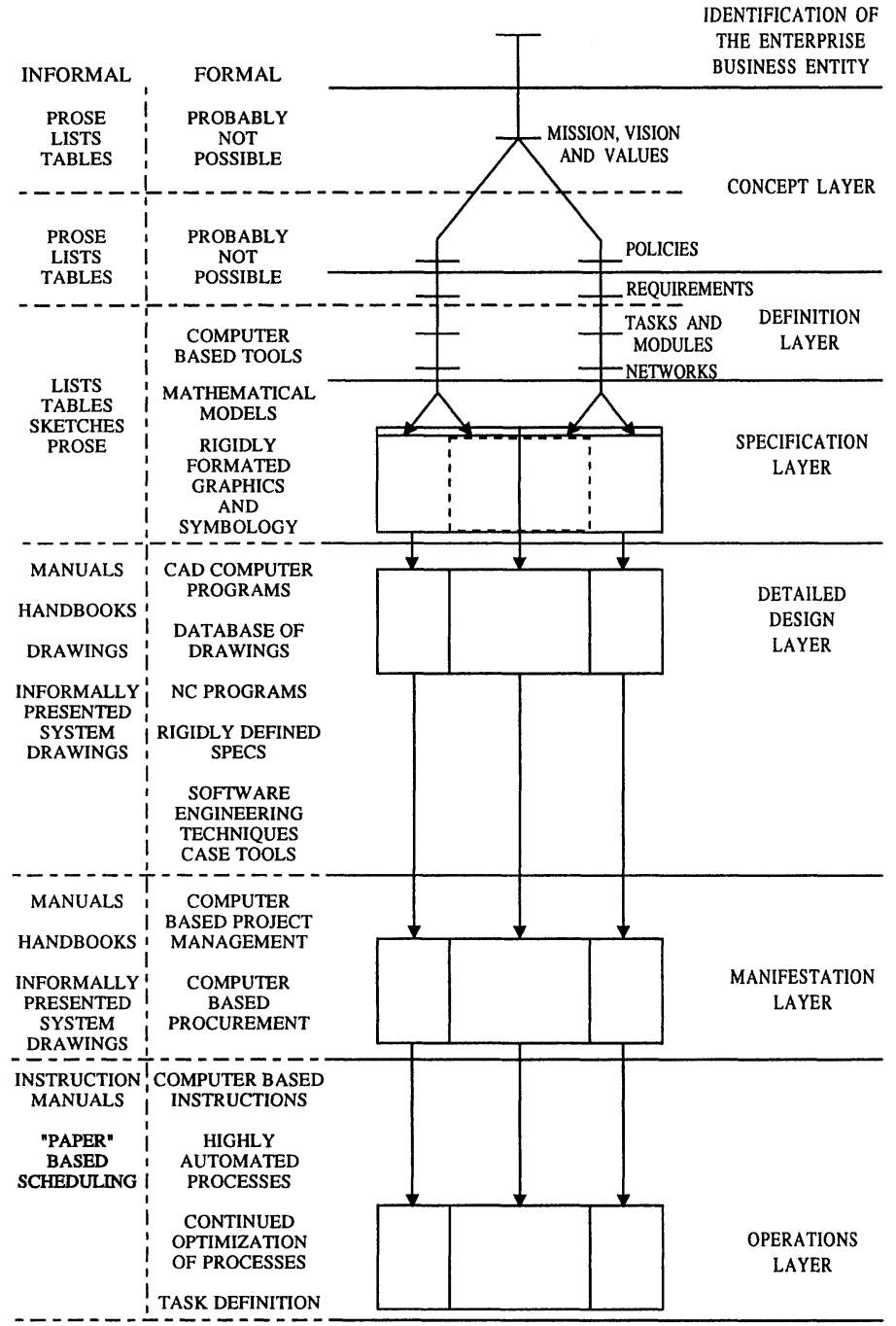

Figure 10 Types of models and tools involved at each phase of the life cycle

\section{SOURCE AND STATUS OF THIS TECHNOLOGY}

The techniques described up to this point in this paper were developed as an activity of the Purdue Laboratory for Applied Industrial Control (PLAIC) at Purdue University, West Lafayette, Indiana. The work was carried out with the 
support and direct cooperation of a group of 12 industrial companies during the period of 1989-1994. This material has been widely published in Purdue reports [Williams et al. (1996)], books [Bernus et al. (1996), Williams (1994)] and technical papers [Rathwell and Williams (1996)], among many others. It has already been successfully used by industrial companies for very large projects in several industries.

This said, we must quickly add that the application of this technology (the methodology and its associated architecture) would profit greatly and expand its use from the following aids:

1. Widely available instructional manuals in print and on the world-wide web.

2. More compatibility and interoperabilty of the several design packages, communications technologies, and related computer system components needed to develop the work benches for applying this technology. Widely accepted standards (from whatever source) are vital here.

3. Much more compatibility in the nomenclature used for the many disciplines which interact in projects of the size and breadth of an enterprise integration system. It is always amazing to see the wide diversity of use and meaning of the same words and phrases across the several disciplines and the resulting misunderstandings that result.

\section{INTRODUCTION AND DEVELOPMENT OF THE CONCEPTS OF GERAM}

\subsection{Origin of the Task Force}

The IFAC/IFIP Task Force on Architectures for Enterprise Integration was formed by IFAC (The International Federation of Automatic Control) and IFIP (The International Federation for Information Processing) in August 1990. It was the first and is, so far, the only such joint operational group established by the two different international scientific or engineering federations. The Task Force was charged to review the field of its title and report its results to the next subsequent IFAC Congress, which was to be held in Sydney, Australia in July 1993.

The Task Force was formed as a group of manufacturing engineers, computer scientists and information technology managers to study, compare and evaluate the different available architectures for enterprise integration which were in the open literature. The basic task assigned the Task Force was to study those architectures and make recommendations for the future development of this field.

\subsection{What is GERAM}

The Task Force early recognized that a single, universally accepted architecture, framework, or model would be a major contribution to the field of enterprise integration. The group first tried the path of finding an acceptable candidate from among those currently available and then extending it as necessary for their purposes.

Failing in this for political rather than technical reasons, the group next resolved that a new architecture should be developed from the best characteristics of the set of existing architectures being studied by the Task Force. It was further decided 
that these same political rather than technological factors again dictated that this new architecture should be developed only as far as the specification stage. The resulting architecture would then become a goal for further development of the existing architectures to give those who succeeded the necessary capabilities to fully serve the field. The specification would also include the necessary application information or methodology.

The new architectural specification would become GERAM, the Generalized Enterprise $\underline{\text { Reference }}$ Architecture and $\underline{\text { Methodology. }}$

\subsection{The Situation Facing the Task Force}

The following observations were developed by the Task Force members as characterizing the Enterprise Reference Modeling Field at that time (September 1991):

1. There are a very large number of architectures or models already in the literature or developed as proprietary projects by many industrial groups.

2. None of these were complete as yet.

3. Most present many of the same concepts but by means of different graphical and mathematical methods.

4. The ancient parable of the group of blind Indian philosophers who attempted to describe an elephant after each had felt only different separate parts, certainly applies here - Each of the proposed architectures is describing the same subject but from widely varied, and very incomplete viewpoints. Thus, the descriptions appear to be very different.

5. The work of the Task Force was to sort all of this out - as noted above. Their first task was to make a comparative analysis of the available models. They would then attempt to distill the needs of the field from these existing proposals.

6. The best solution would be to be able to adopt one existing model or architecture as best - failing this, build on an existing system by supplying the apparently missing capabilities - the last resort would be to specify a whole new one from the characteristics of several of the others.

\subsection{Early Work of the Task Force}

The early work of the Task Force quickly showed:

1. There are two basic types of enterprise integration architectures available today: (1) those which describe the architecture or physical structure of some component or part of the integrated system such as the computer system or the communications system and (2) those which present an architecture or structure of the project which develops the integration, i.e., those that illustrate the life cycle of the project developing the integrated enterprise. This was discussed earlier in the PERA presentation.

2. The experience of many CIM program groups world-wide has shown the value of a reference architecture of the second type above in guiding the separate stages of planning, establishment, analysis, specification, detailed design, construction and commissioning, and operation of projects for the 
integration of information and manufacturing activities in industrial plants and indeed all types of enterprises everywhere.

3. Thus, the most valuable architectures are those which model or describe the structure of the integration programs themselves, i.e., the developmental and application stages in the life history of the program. These were labeled as Type 2 architectures.

4. These Type 2 architectures will include as vital component parts many examples of the other major type of reference architectures. These latter architectures, to be known as Type 1, model or describe the structure of the computer system and/or of other major components which comprise the overall integration system as finally developed. The vast majority of the socalled reference architectures in the literature today are of this second type.

5. The Task Force also determined that it is vital that the Type 2 reference architecture be accompanied by a methodology which gives detailed instructions to user project development groups on how to use the architecture to guide the conduct and progress of their study. The methodology should also detail the nature and use of all available techniques and tools valuable to the user group at each stage of the development and operation of the integration program and/or project.

6. Enterprise integration is a very complex and highly detailed endeavor. Similarly, the reference architectures which describe this endeavor are also complex and highly detailed. As a result, none of the candidate architectures and associated methodologies were, at that time, completely developed, described and documented. However, in each case the path to their ultimate completion was clear either from the work of the architectural development group themselves and their future plans or from the associated work of other groups, including the Task Force.

7. Each of the studied architectures and their associated methodologies should be extended by the original development groups or others to become a complete architecture and methodology for guiding enterprise integrating programs from initial conception to their construction and use.

8. It would also be possible, and perhaps more rewarding, to combine the best parts of each of the candidate architectures to capture the possible synergy in a new or combined architecture.

9. The more common type of architecture in the literature today, as noted in Item 4 above, is that of Type 1 above which shows the structure of the integrating computer system, for example. These readily become one of the tools or techniques listed in Item 5 above, but are only part of the larger overall architecture of the development program which produces the desired integrated enterprise.

\subsection{The Studied Architectures and the Task Force's Recommendations of Each}

In its work, the Task Force concluded that there were only three Architectures of the Type 2 variety in the open literature which were developed far enough to be valuable for study by the Task Force. These three architectures were: 
1. CIMOSA - As developed by the AMICE Consortium under the ESPRIT Program of the European Community [see (Bernus et al. (1996)].

2. GRAI-GIM - As developed by the GRAI Laboratory of the University of Bordeaux, Bordeaux, France, under its own research program for production management systems and with the aid of ESPRIT [see Bernus et al. (1996)].

3. PERA - The Purdue Enterprise Reference Architecture and its associated Purdue Methodology - As described in the earlier part of this paper.

CIMOSA can be characterized by its "cube" model as shown in Figure 11. GRAI-GIM is shown in Figure 12.

\section{THE DEGREE OF GENERICITY}

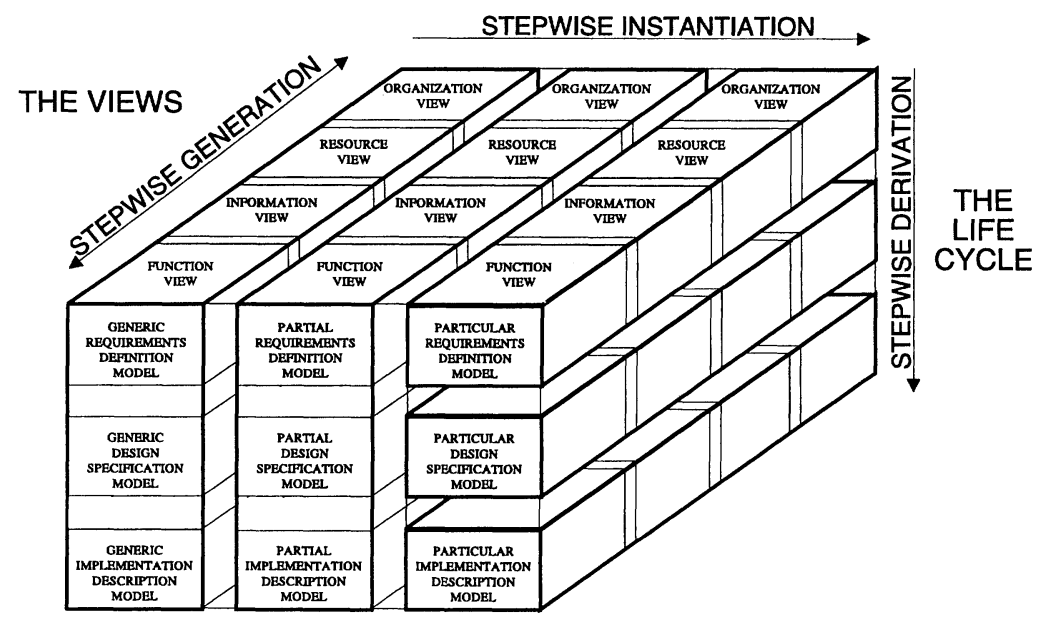

Figure 11 The CIMOSA architectural framework -- the CIMOSA cube

Note that the Identification and Concept Layers are missing from CIMOSA since they assume this data is already available. Likewise the Manifestation and Operation Layers shown in PERA are missing since again CIMOSA assumes this is handled by others.

CIMOSA is particularly noted for its espousal of three separate life cycles in parallel, labeled Generic, Partial, and Particular. Generic represents those enterprise integration factors generic to all enterprises. Partial are those generic to a particular industry, and the Particular represents the enterprise in question. CIMOSA recommends proceeding from Generic through to Particular to take advantage of existing knowledge in developing a Particular system. Note also the Views dimension which permits a reduction in modeling complexity but considering only certain aspects of the system in any one model. 


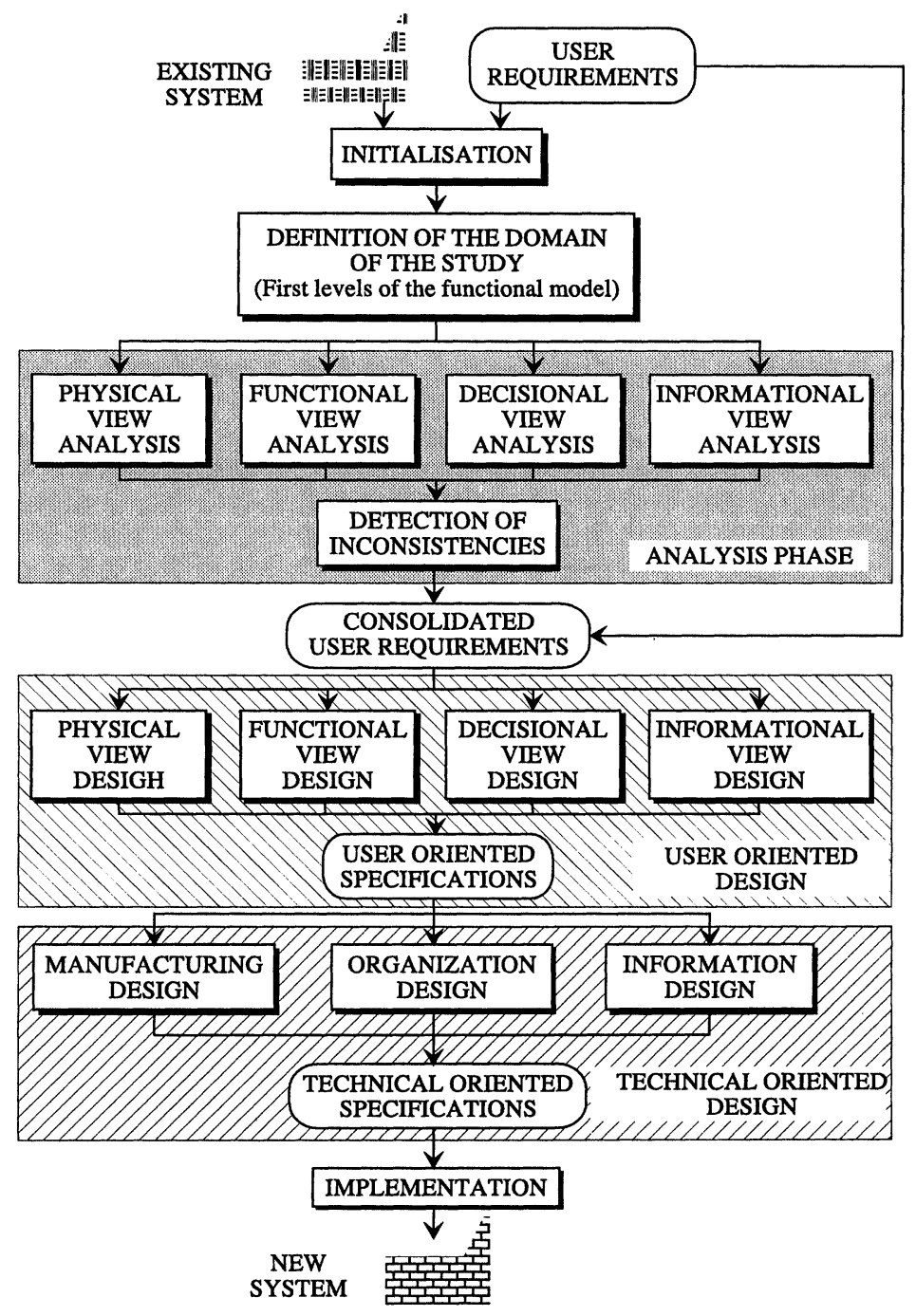

Figure 12 The GRAI-GIM life cycle diagram

GRAI-GIM considers the Identification and Concept Layers as important for the enterprise integration study but does not include a Build and Operations regime since their aim is only to prepare the design for the new system.

Space does not permit a further critical description of the CIMOSA and GRAIGIM enterprise reference architectures in this paper. Interested readers are urged to consult some of the references in the bibliography of this paper. The abovelisted figures should be compared to the corresponding PERA figures presented earlier to show the tremendous differences in presentation forms facing the Task Force in its early work. 


\subsection{The Origin of GERAM}

Dr. Francois Vernadat, a Task Force member, organized a Special Session on Enterprise Modeling and Integration for the ICARCV'94 Conference to be held in Singapore in November 1994. This Special Session formed a major opportunity to kick-off the development of the consolidated architecture recommended earlier by the Task Force .

It was further agreed that a title was needed for this new architecture, and that of

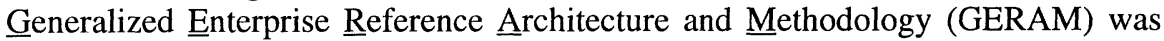
selected as a highly suitable one. The Special Session would then be a collection of papers prepared by Task Force members outlining the requirements for GERAM and the contributions which each of the candidate architectures could make towards it.

As the only active members of the Task Force who were not already deeply involved in developing and promoting their own Enterprise Reference Architecture, Dr. Peter Bernus and Dr. Laszlo Nemes were requested to prepare a paper giving an initial specification and discussion of GERAM.

This paper pointed out several aspects of Enterprise Reference Architectures which had not previously been widely discussed by the Task Force members in their meetings and correspondence. These were:

1. The expansion of the coverage of the Architecture to cover a much wider range of applications:

(a) Products;

(b) Enterprises Producing These Products;

(c) Enterprise Integration Companies Carrying out the Development of Enterprise (b) above; and

(d) Strategic Enterprise Management.

This expanded coverage was described by Bernus and Nemes as the "recursivity" of GERAM [Bernus and Nemes (1996)].

2. Definition of Six Different Components of the Generic Enterprise Reference Architecture and Methodology:

(a) The Generic Enterprise Reference Architecture itself (GERA);

(b) The Generic Enterprise Engineering Integration Methodology (GEEM);

(c) Generic Enterprise Modeling Tools and Languages (GEMT and L);

(d) Generic Enterprise Models (GEM);

(e) Generic Enterprise Modules (GM); and

(f) Generic Ontological Theories (GT).

They also proposed a so-called "matrix model" of GERAM. This latter was a slight modification of the generic mapping tool of the Task Force's 1993 Triennial Report [Bernus et al. (1996)] which by definition serves this purpose since it had been the basis for mapping the characteristics of all studied architectures in the Task Force's previous work.

The "matrix" model for GERAM (Figure 13) was developed by combining the distinctive characteristics of each of three studied architectures into one diagram. It is easy to recognize the three classes of genericity from CIMOSA 
응
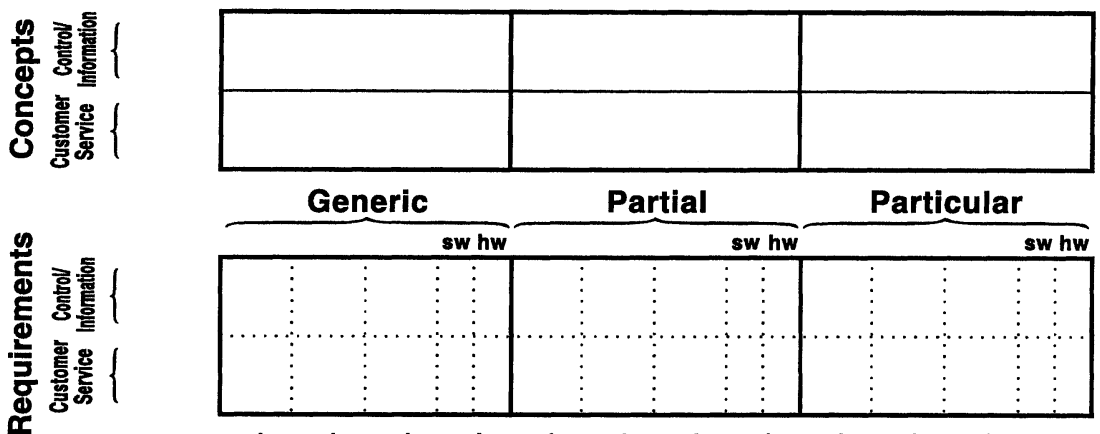

sw hw sw hw sw hw sw hw sw hw sw hw sw hw sw hw sw hw sw hw sw hw sw hw

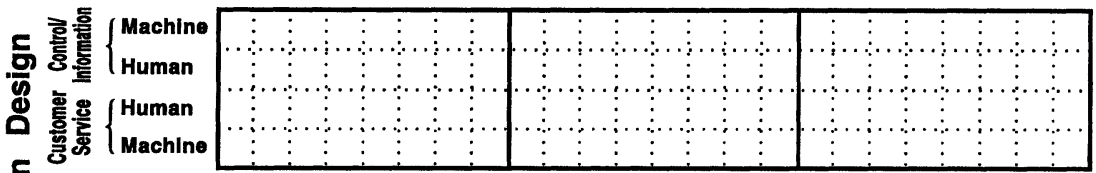

흠

矛边 Machlne
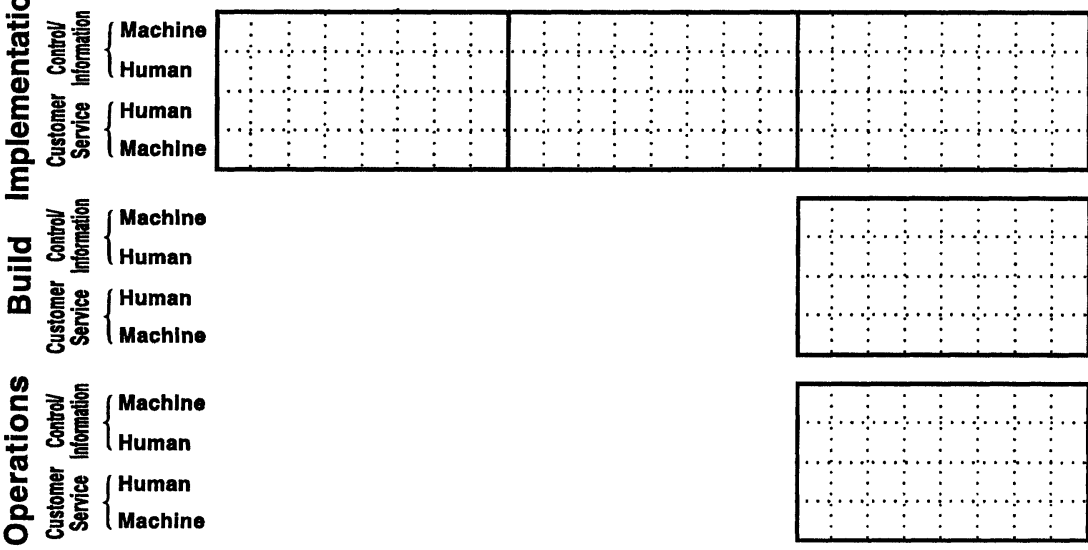

\begin{tabular}{|c|c|c|c|c|c|c|c|c|c|c|c|}
\hline 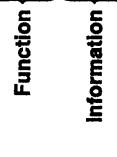 & 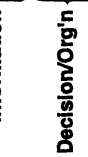 & 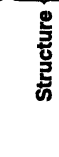 & 홀 & 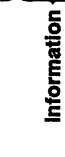 & & 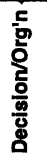 & 氙 & & & & \\
\hline
\end{tabular}

Figure 13 Original Task Force architecture design diagram, the "matrix" model

(Generic, Partial, and Particular); the life cycle of PERA (somewhat modified to recognize the different titles used by CIMOSA); and the views of GRAI-GIM and 
CIMOSA along the bottom. Thus it was possible to map the capabilities of each on these diagrams and make a graphical comparison of them.

However, when one wished to discuss GERAM itself, this diagram became too complicated (note that the Human-Machine separation of PERA is now horizontal and does not follow the Life Cycle).

It was possible to manipulate this diagram to develop a companion threedimensional figure (Figure 14) which was much more expressive of GERAM and its derivation. Here the reader can see that the CIMOSA cube is now in its original form (Figure 11) as is GRAI-GIM in the right-hand column of Figure 14.

PERA becomes the front face of the three-dimensional block figure as shown in Figure 15. This is because PERA does not require the view structure proposed by CIMOSA and retained in GERAM. It can, of course, be used if desired but is not considered necessary. PERA appears in all three rows of life cycles.

\section{RECENT WORK}

A major part of the recent activities of the Task Force have been involved with the International Standards Organization (ISO) to standardize the requirements for a "complete" generalized enterprise reference architecture and methodology -- not GERAM specifically but all enterprise reference architectures and methodologies which aspire to use the completeness title. In this work the Task Force is cooperating with ISO/TC184/SC5/WG1, entitled Modeling and Architecture. The proposed standard is near Committee Draft form (now ISO/WD 15704) and is expected to be released for initial consideration and initial balloting in the near future. It is formally entitled, Requirements for Enterprise Reference Architecture and Methodologies.

\section{SUMMARY}

PERA, as described in this paper, along with its associated methodology for application, is enjoying widespread use in industry for application to all types of industries. It is also being widely studied in educational institutions around the world. It seems to be providing the necessary guidance for enterprise engineering integration projects which had been missing up to this time. We look forward to ever increasing use.

GERAM provides the same capabilities as PERA through its inheritance from the use of PERA in developing GERAM. It uses a somewhat more complicated graphical representation, however, through the desire of the Task Force members to be able to readily map all the other architectures studied by the Task Force into this one structure. 


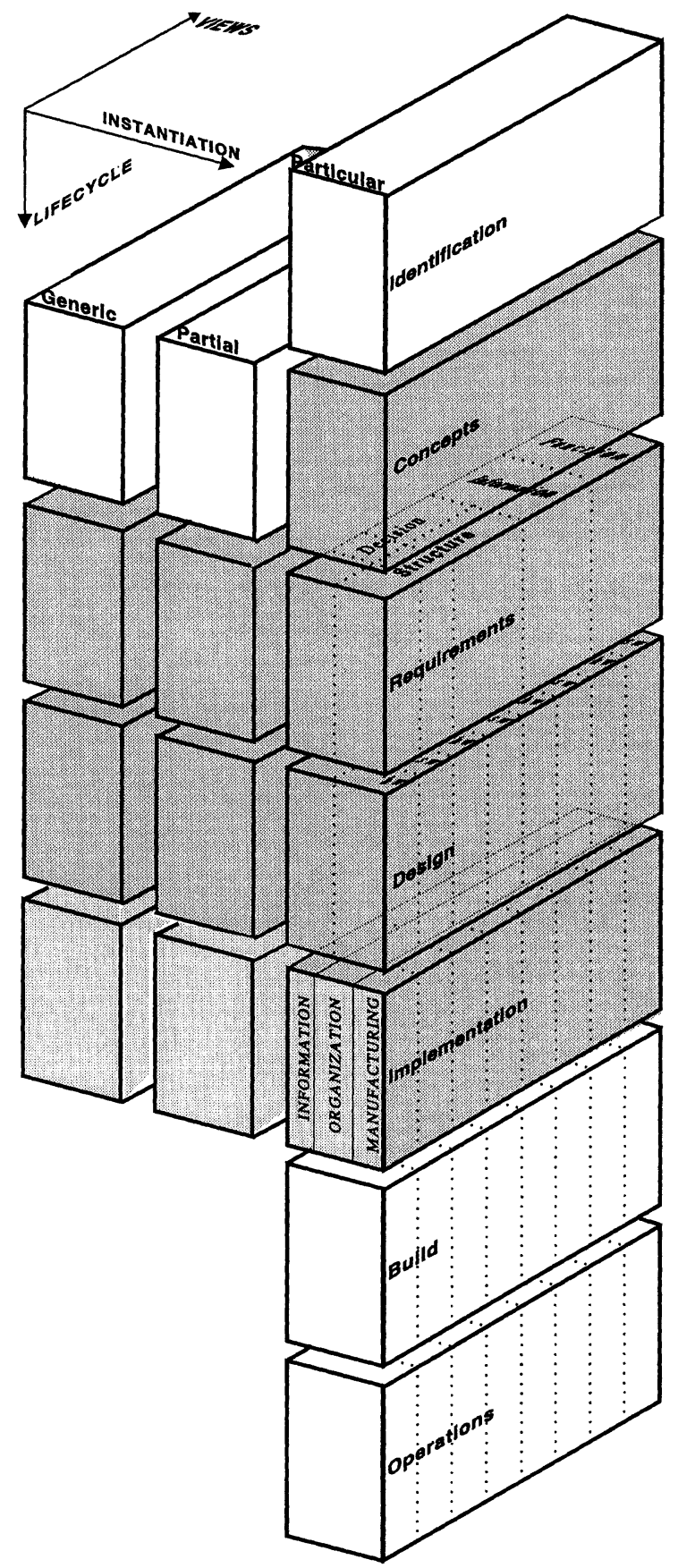

Figure 14 Representation of CIMOSA "cube" and the GRAI-GIM structured approach (far right column) on the reconstructed matrix 


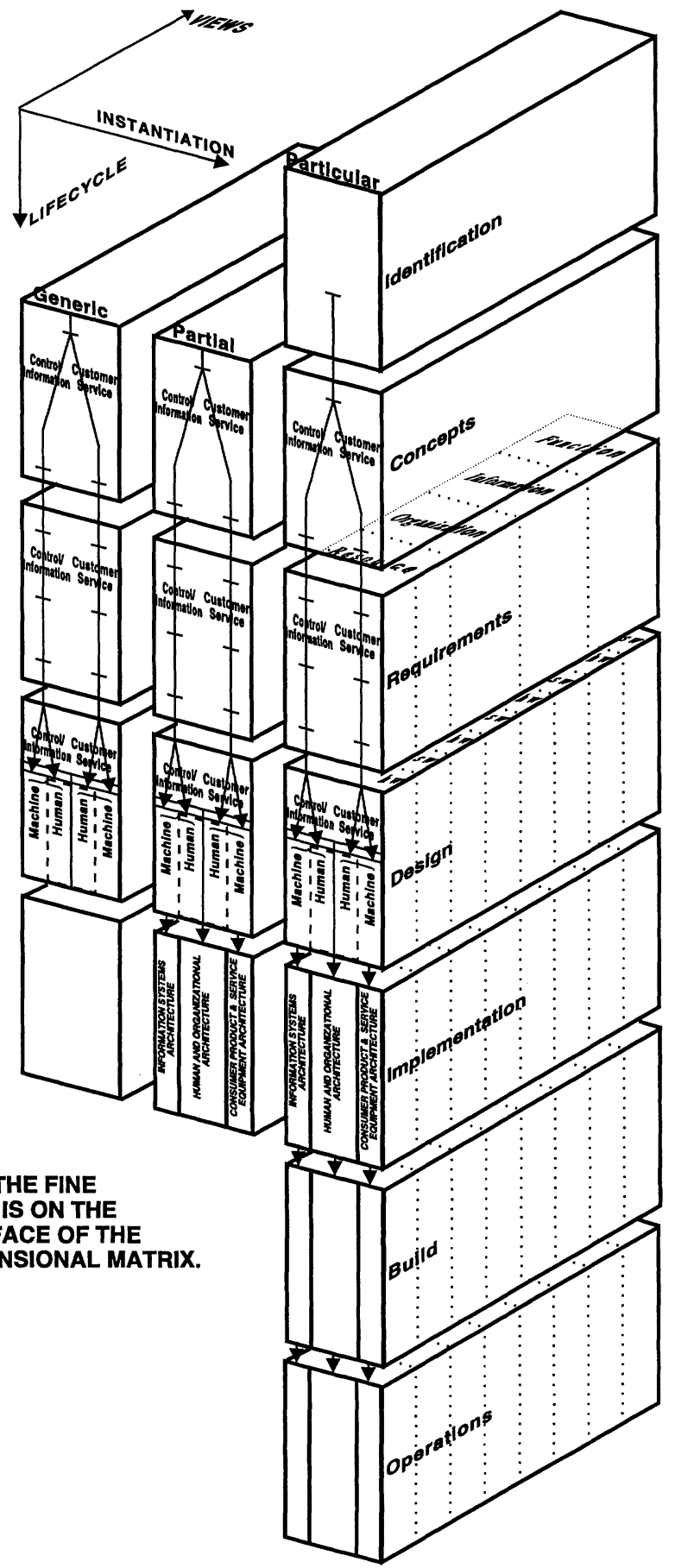

NOTE THAT THE FINE

STRUCTURE IS ON THE

FRONT SURFACE OF THE

THREE-DIMENSIONAL MATRIX

THREE-DIMENSIONAL MATRIX. 
Bernus, P., and Nemes, L. (1996) Modelling and Methodologies for Enterprise Integration, Chapman and Hall, London. Contains papers on all the architectures discussed and related research by Task Force members and others.

Bernus, P., Nemes, L., and Williams, T.J. (1996), Architectures for Enterprise Integration, Chapman and Hall, London.

Checkland, P.B. (1985) Towards a Systems Based Methodology for Real-World Problem Solving, in Systems Behaviour (ed. Open System Group), Third Edition, Harper \& Row, Publishers, London, UK.

Rathwell, G.A., and Williams, T.J. (1996) Use of the Purdue Enterprise Reference Architecture and Methodology in Industry (the Fluor Daniel Example), in Modeling and Methodologies for Enterprise Integration (eds. P. Bernus and L. Nemes), Chapman and Hall, London.

Sage, A.P. (1992) Systems Engineering. John Wiley and Sons, Inc., New York, NY.

Thomé, B. (ed.) (1993) Systems Engineering, Principles and Practice of ComputerBased Systems Engineering. John Wiley \& Sons, Inc., New York, NY, USA.

Williams, T.J. (1961) Systems Engineering for the Process Industries. McGrawHill Book Company, New York, NY, USA.

Williams, T.J. (1994), The Purdue Enterprise Reference Architecture, Computers in Industry, 24 (2-3), 141-158.

Williams, T.J., Rathwell, G.A., and Li, Hong (eds.) (1996) A Handbook on Master Planning and Implementation for Enterprise Integration Programs. Report 160, Purdue Laboratory for Applied Industrial Control, Purdue University, W. Lafayette, IN.

\section{BIOGRAPHIES}

Theodore J. Williams is Professor Emeritus of Engineering and Director Emeritus of the Purdue Laboratory for Applied Industrial Control, Purdue University, West Lafayette, Indiana, USA. He was the Founding Chairman of the IFAC/IFIP Task Force on Architectures for Enterprise Integration. He was also the Founding Chairman of IFIP Technical Committee TC-5, Computer Applications in Technology. He is a Past-President of the Instrument Society of America, of the American Automatic Control Council and of the American Federation of Information Processing Societies.

Hong Li is Senior Consultant, Claremont Technology Group, Inc. Dr. Li received his Ph.D. in industrial engineering from Purdue University, West Lafayette, Indiana, USA, in 1994. He received his MS in systems engineering from the University of Science and Technology of Beijing, China before coming to the United States. His research interests are enterprise reference architectures and methodologies and their application in industry, and production planning and scheduling. 